\title{
The efficacy of ultrasound-guided erector spinae plane block after mastectomy and immediate breast reconstruction with a tissue expander: a randomized clinical trial
}

\author{
Sukhee Park ${ }^{1, *}$, Joohyun Park ${ }^{2, *}$, Ji Won Choi ${ }^{2}$, Yu Jeong Bang ${ }^{2}$, Eun Jung $\mathrm{Oh}^{2}$, Jiyeon Park ${ }^{1}$, \\ Kwan Young Hong ${ }^{2}$, and Woo Seog Sim ${ }^{2}$ \\ 'Department of Anesthesiology and Pain Medicine, International St. Mary's Hospital, Catholic Kwandong University School of Medicine, Incheon, \\ Korea \\ ${ }^{2}$ Department of Anesthesiology and Pain Medicine, Samsung Medical Center, Sungkyunkwan University School of Medicine, Seoul, Korea
}

Received September 2, 2020

Revised November 18, 2020

Accepted November 23, 2020

Handling Editor: Francis S. Nahm

\section{Correspondence}

Ji Won Choi

Department of Anesthesiology and Pain

Medicine, Samsung Medical Center,

Sungkyunkwan University School of

Medicine, 81 Irwon-ro, Gangnam-gu,

Seoul 06351, Korea

Tel: +82-2-3410-6590

Fax: +82-2-3410-6626

E-mail: jiwon0715.choi@samsung.com

*These authors contributed equally to this work.

\begin{abstract}
Background: We aimed to investigate the analgesic efficacy of an erector spinae plane block (ESPB) in immediate breast reconstruction (IBR) with a tissue expander. Methods: Adult women undergoing IBR with a tissue expander after mastectomy were randomly assigned to either intravenous patient-controlled analgesia (IV-PCA) alone (group P) or IV-PCA plus ESPB (group E). The primary outcome was the total amount of opioid consumption during 24 hours postoperatively between the two groups. Secondary outcomes were patient satisfaction, pain score at rest and on shoulder movement using numerical rating scale, incidences of postoperative nausea and vomiting (PONV), and a short form of the brief pain inventory (BPI-SF) at 3 and 6 months after surgery between the groups.

Results: Fifty eight patients completed the study. At 24 hours postoperatively, total opioid consumption was significantly less in group $\mathrm{E}$ than in group $\mathrm{P}(285.0 \pm 92.0$, 95\% confidence interval [Cl]: 250.1 to 320.0 vs. $223.2 \pm 83.4,95 \% \mathrm{Cl}: 191.5$ to 254.9, $P=0.005)$. Intraoperative and cumulative PCA fentanyl consumption at 3,6 , 9 , and 24 hours were also less in group $\mathrm{E}$ than in group $\mathrm{P}(P=0.004, P=0.048, P$ $=0.020, P=0.036$, and $P<0.001$, respectively). Patient satisfaction was higher in group $E(6.9 \pm 1.8$ vs. $7.8 \pm 1.4, P=0.042)$. The incidences of PONV was similar. Conclusions: The ESPB decreased postoperative opioid consumption and increased patient satisfaction without significant complications after IBR with a tissue expander after mastectomy.
\end{abstract}

Key Words: Analgesia; Breast Implants; Breast Neoplasms; Mastectomy; Nerve Block; Pain, Postoperative; Patient Satisfaction; Reconstructive Surgical Procedures; Tissue Expansion Devices; Ultrasonography, Interventional.

\section{INTRODUCTION}

Breast cancer is one of the most common cancers in women that needs surgery worldwide [1]. Immediate breast reconstruction (IBR) with a tissue expander after mastectomy is currently favored by many patients because of improved body image and self-esteem [2]. However, this method is usually associated with more severe postopera- (c) This is an open-access article distributed under the terms of the Creative Commons Attribution Non-Commercial License (http://creativecommons.org/licenses/by-nc/4.0/), which permits unrestricted non-commercial use, distribution, and reproduction in any medium, provided the original work is properly cited.

(c) The Korean Pain Society, 2021
Author contributions: Sukhee Park: Writing/manuscript preparation; Joohyun Park: Writing/manuscript preparation; Ji Won Choi: Writing/ manuscript preparation; Yu Jeong Bang: Investigation; Eun Jung Oh: Writing/manuscript preparation; Jiyeon Park: Investigation; Kwan Young Hong: Writing/manuscript preparation; Woo Seog Sim: Supervision. 
tive pain than is mastectomy alone or flap-based reconstructions, because of musculocutaneous expansion by the implant $[2,3]$. Since adequate postoperative pain management is known to improve the quality of recovery and reduces progression to persistent postsurgical pain (PPP), much effort should be taken to control postoperative pain using multimodal analgesia $[4,5]$.

The erector spinae plane block (ESPB) was first introduced by Forero et al. [6] in 2016 for management of neuropathic pain in the thoracic area. It is a simple method of injecting local anesthetics between the transverse process (TP) of the thoracic vertebrae and the erector spinae muscle (ESM) [6]. However, there is conflicting opinion as to whether this block may be effective in managing postoperative pain. Several clinical studies have shown that the ESPB may be effective in postoperative pain control for various types of thoraco-abdominal surgery [7-11], while, there have been some contrary results suggesting that the ESPB has a limited effect on postoperative pain control [12-14].

Therefore, in this study, we evaluated the analgesic efficacy and clinical applicability of the ESPB in patients undergoing IBR with a tissue expander after mastectomy. We hypothesized that total opioid consumption during 24 hours postoperatively would be reduced in patients receiving ESPB (group E) compared to the control group (group P).

\section{MATERIALS AND METHODS}

\section{Study design}

This prospective randomized clinical trial was approved by the Institutional Review Board of Samsung Medical Center (IRB no. SMC 2018-08-032-003) and was registered on the Clinical Trial Registry of Korea (КCT0003465). Written informed consent was obtained from all participants.

Patients with American Society of Anesthesiologists physical status I-II, aged 20-70 years, scheduled for an elective unilateral IRB with a tissue expander after mastectomy, between February 2019 and August 2019, at Samsung Medical Center, Seoul, Korea, were included in this study. The exclusion criteria included: patients who refused to participate in the study and had chronic pain, psychological disorders, a known allergy to the study drugs (especially local anesthetics), a history of drug abuse, coagulation disorders, infection at the injection site, and renal dysfunction (preoperative serum creatinine level $>2.0 \mathrm{mg} / \mathrm{dL}$ ).

A total of 60 patients were included, with 30 patients assigned to each group. An internet program (www.random- izer.org) was used for randomization in a 1:1 ratio, to allocate enrolled patients to group $\mathrm{P}(\mathrm{n}=30)$ or group $\mathrm{E}(\mathrm{n}=$ 30). We did not perform the sham block and both patients and physicians (Choi J and Bang Y) could not be blinded to the type of pain control. Other investigators, (Park S and Park J) for outcome assessment, were blinded to group enrollment, as they were not involved in performing the procedure.

\section{The ESPB procedure}

The ESPB was done by an experienced anesthesiologist (Choi J) with the attendance of another author (Bang Y) in a separate room for the procedure prior to general anesthesia. Patients were in a prone position with standard monitoring, including electrocardiography (ECG), oxygen saturation $\left(\mathrm{SpO}_{2}\right)$, and noninvasive blood pressure (NIBP). After confirming the surgical site (right or left), we marked at the $3 \mathrm{~cm}$ laterally to the $\mathrm{T} 4$ and $\mathrm{T} 5$ spinous processes using an ultrasound-guided linear probe (6 to $13 \mathrm{~Hz}$, Sonosite M-turbo ${ }^{\circledR}$; Fujifilm Sonosite, Inc., Bothell, WA). Then, we sterilized the patient's skin aseptically with $2 \%$ chlorohexidine and alcohol. The probe was also covered with a sterile sheath. After the TP of T4 and the overlying deep ESM were visualized, we inserted the needle (22 gauge, 89 mm; Hakko Co., Ltd., Nagano, Japan) to contact the T4 TP with an in-plane technique in a cranial to caudal direction. When the tip of the needle touched the T4 TP on the imaging, $1 \mathrm{~mL}$ of normal saline was injected to lift the ESM from the bony shadow of the TP. We also injected $30 \mathrm{~mL}$ of $0.375 \%$ ropivacaine. No additional sedatives or analgesics were administered during the procedure.

\section{Standard anesthesia protocol}

All patients received a standard general anesthesia protocol. After entering the operating room, all patients were given standard monitoring (ECG, $\mathrm{SpO}_{2}$, and NIBP) and Bispectral Index ${ }^{\mathrm{TM}}$ (BIS $^{\mathrm{TM}}$; Medtronic, Mineapolis, $\mathrm{MN})$. Anesthesia induction was done with propofol (1.5$2 \mathrm{mg} / \mathrm{kg})$, sevoflurane, and rocuronium $(0.8 \mathrm{mg} / \mathrm{kg})$, and the inhalation anesthetic concentration was adjusted to maintain BIS for $40 \pm 5$. Endotracheal intubations used a 7.0 diameter tube. During surgery, the fentanyl $25 \mu \mathrm{g}$ was administered intravenously when blood pressure was increased by $20 \%$ compared to baseline, and ephedrine $5 \mathrm{mg}$ or atropine $2.5 \mathrm{mg}$ was administered intravenously when blood pressure decreased by $20 \%$ compared to baseline or heart rate fell below 40 beats/min. Approximately 30 minutes before the end of surgery, palonosetron $\mathrm{HCl} 0.075$ $\mathrm{mg}$ and ketorolac $30 \mathrm{mg}$ were administered intravenously. When the patient was properly recovered from muscle 
relaxation, tracheal extubation was done and the patient was transferred to the recovery room. All patients received intravenous patient-controlled analgesia (IV-PCA) using a device (Automed3200; Acemedical, Goyang, Korea), which was started at the end of the surgery. The PCA was initially set to deliver with a continuous infusion of fentanyl $10 \mu \mathrm{g}$ hourly, with a bolus infusion of $10 \mu \mathrm{g}$ on each press and 10 minutes of lockout time. The PCA was allowed to intermittently turn off if patients had nausea, vomiting, or little pain. If the numeric rating scale (NRS) pain score was over 4 in the recovery room or surgical ward, $0.01 \mathrm{mg} / \mathrm{kg}$ of hydromorphone was administered intravenously as a rescue analgesic.

\section{Postoperative outcome assessment}

The 11-point NRS, which ranges from ' 0 ' (no pain) to ' 10 ' (worst pain), was used to evaluate the postoperative pain. The IV-PCA consumption, pain score at rest and on shoulder abduction or internal rotation, and presence of PONV were recorded at $3,6,9$, and 24 hours postoperatively by two investigators (Park S and Park J). Doses of hydromorphone administered to patients were converted to IV fentanyl equianalgesic doses (fentanyl $100 \mu \mathrm{g}=$ hydromorphone $2 \mathrm{mg}$ ). The patient satisfaction score for pain management at 24 hours after surgery (from ' 0 ' [worst] to ' 10 ' [best]) was also recorded. Telephone interviews to access the PPP were done at 3 and 6 months after surgery. The verbally administered 12 items of the short form of the brief pain inventory (BPI-SF) was used to evaluate the pain intensity and pain interference with functional activities [15]. The 12 items are follows: presence or absence of pain during the previous 24 hours, 4 items of pain intensity measurements (present, least, average, and worst pain), 7 items measuring pain interference with function (general activity, mood, walking ability, normal work, relations with other people, sleep, and enjoyment of life). Each item was rated on the NRS score (from ' 0 ' = [no pain] to ' 10 ' [worst pain imaginable], or as ' 0 ' [no interference] to ' 10 ' [interferes completely]).

Primary outcome was the total amount of postoperative opioid consumption during the first 24 hours. Secondary outcomes were the postoperative NRS pain score, patient satisfaction, incidence of PONV, and response to the BPISF.

\section{Sample size calculation and statistical analysis}

We hypothesized that the total opioid consumption during the first 24 hours after surgery would be decreased by $30 \%$ in the E group (ESPB group) relative to the P group (control group) based on a previous study [16]. With a power of $90 \%$ and a significance level of 0.05 , the number of participants needed to find the statistical difference between groups was 27 patients for each group. Assuming a 10\% dropout rate, we enrolled a total of 60 patients for this study.

Continuous variables are shown as mean \pm standard deviation or as median (interquartile range) according to normality of the data distributions and were compared by using a $t$-test or Wilcoxon rank-sum test as appropriate. Normality of data distributions were assessed by using the Kolmogorov-Smirnov test. Categorical variables are presented as frequency (percentage) and were compared by using a chi-square test or Fisher's exact test. Bonferroni correction was used for multiple comparisons. All reported $P$ values were two-sided and $P<0.05$ was considered statistically significant. All statistical analyses were performed using SPSS 25.0 (IBM Co., Armonk, NY).

\section{RESULTS}

A total of 60 patients were initially enrolled in the study. Two patients were excluded for refusing pain assessment; the remaining 58 patients completed the study (Fig. 1). The baseline characteristics and perioperative clinical data between the two groups were comparable (Table 1).

As shown in Table 2, the total amount of opioid con-

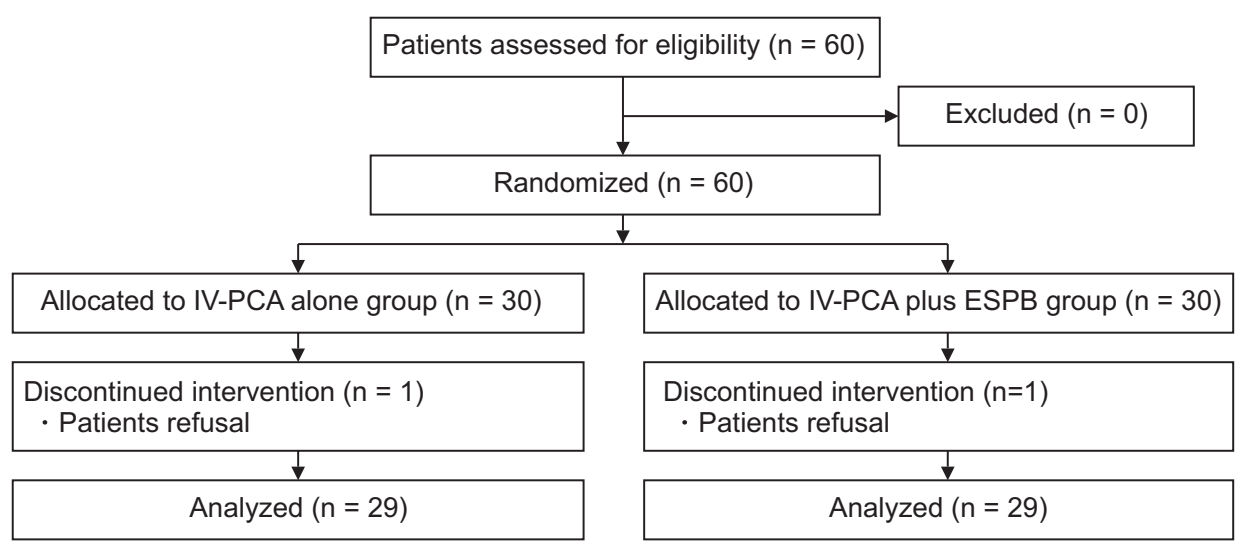

Korean J Pain 2021;34(1):106-113
Fig. 1. Consolidated standards of reporting trials flow diagram. IV-PCA: intravenous patient-controlled analgesia, ESPB: erector spinae plane block.

https://doi.org/10.3344/kjp.2021.34.1.106 
sumption at 24 hours postoperatively was significantly less in group E than in group P $(285.0 \pm 92.0 \mu \mathrm{g}, 95 \%$ confidence interval [CI]: 250.1 to 320.0 vs. $223.2 \pm 83.4 \mu$; $95 \%$ CI: 191.5 to $254.9, P=0.005$ ). There was a significant reduction in the consumption of intraoperative fentanyl in group E (46.4 $\pm 33.8 \mu \mathrm{g}, 95 \%$ CI: 33.3 to 59.5 vs. $21.6 \pm 29.7 \mu \mathrm{g}, 95 \%$ CI: 10.3 to $32.8, P=0.004)$. Likewise, postoperative cumulative PCA fentanyl consumption at 3, 6, 9, and 24 hours after surgery in group E was significantly less than in group P (Table 2). The patient satisfaction for pain management assessed at 24 hours after surgery in group $\mathrm{E}$ was significantly greater $(6.9 \pm 1.8$ vs. $7.8 \pm 1.4, P=0.042)$ than in group P. However, the proportion of postoperative rescue analgesic requirements in post-anesthesia care unit and surgical ward, and the incidence of postoperative nausea and vomiting, were not different between the groups.

Table 1. The baseline characteristics and perioperative clinical data

\begin{tabular}{lcc}
\hline \multicolumn{1}{c}{ Variables } & $\begin{array}{c}\text { IV-PCA alone } \\
(\mathrm{n}=29)\end{array}$ & $\begin{array}{c}\text { IV-PCA plus ESPB } \\
(\mathrm{n}=29)\end{array}$ \\
\hline Age $(\mathrm{yr})$ & $43.9 \pm 7.9$ & $44.7 \pm 8.9$ \\
Weight $(\mathrm{kg})$ & $59.8 \pm 8.9$ & $57.4 \pm 10.7$ \\
Height $(\mathrm{cm})$ & $161.1 \pm 5.2$ & $160.0 \pm 4.7$ \\
BMI $\left(\mathrm{kg} / \mathrm{m}^{2}\right)$ & $22.9 \pm 3.1$ & $22.4 \pm 3.5$ \\
ASA status $(\mathrm{I} / \mathrm{II})$ & $23 / 6$ & $25 / 4$ \\
Hemoglobin $(\mathrm{mg} / \mathrm{L})$ & $12.8 \pm 1.0$ & $12.5 \pm 1.3$ \\
Duration of anesthesia $(\mathrm{min})$ & $246.3 \pm 38.6$ & $246.8 \pm 39.8$ \\
\hline
\end{tabular}

Values are presented as mean \pm standard deviation or number only. IV-PCA: intravenous patient-controlled analgesia, ESPB: erector spinae plane block, BMI: body mass index, ASA: American society of anesthesiologists.
Although median NRS scores on movement during the 24 hours after surgery was lower in group E, these were not significantly different between the groups (Table 3). No other complications were observed during this study in either group.

The telephone interview respondents at 3 and 6 months postoperatively were $49(84.5 \%)$ and $46(79.3 \%)$, respectively. Of the respondents, $27(55.1 \%)$ at 3 months and 23 $(50.0 \%)$ at 6 months postoperatively claimed that they had surgery-related pain during the previous 24 hours; these did not show significant differences between the groups. SF-BPI regarding pain interference at 3 and 6 months after surgery were also similar between the groups (Table 4).

\section{DISCUSSION}

In this study, the ESPB plus IV-PCA group showed less total opioid consumption and higher patient satisfaction than the IV-PCA alone group on the first day after undergoing IBR after mastectomy. Intraoperative consumption of fentanyl was also lower in the ESPB plus IV-PCA group.

The ESPB can be easily and safely done by advancing the needle towards the $\mathrm{TP}$, contacting the $\mathrm{TP}$, and injecting a local anesthetic to separate the longitudinally located ESM from the TP [17]. However, according to recent cadaveric studies, there were differing results about the spread of anesthetics. Some reports indicated that the dye spread longitudinally along the ESM into the thoracic paravertebral space or epidural space $[18,19]$, but other studies showed that an ESPB followed the fascial planes with either an unpredictable spread or no spread of dye anteriorly to the

Table 2. Postoperative variables in the first 24 hours

\begin{tabular}{|c|c|c|c|}
\hline Outcomes & IV-PCA alone $(n=29)$ & IV-PCA plus ESPB $(n=29)$ & $P$ value \\
\hline Total fentanyl consumption during 24 hours postoperatively $(\mu g)^{*}$ & $285.0 \pm 92.0(250.1-320.0)$ & $223.2 \pm 83.4(191.5-254.9)$ & 0.005 \\
\hline Intraoperative fentanyl consumption $(\mu \mathrm{g})$ & $46.4 \pm 33.8(33.3-59.5)$ & $21.6 \pm 29.7(10.3-32.8)$ & 0.004 \\
\hline \multicolumn{4}{|l|}{ Cumulative PCA fentanyl consumption ( $\mu \mathrm{g})$} \\
\hline 3 hours & $85.3 \pm 37.9(65.1-105.5)$ & $56.4 \pm 28.9(44.2-68.6)$ & 0.048 \\
\hline 6 hours & $126.5 \pm 45.9(95.7-157.4)$ & $76.3 \pm 31.9(60.9-91.7)$ & 0.020 \\
\hline 9 hours & $144.1 \pm 50.9(113.3-174.9)$ & $96.7 \pm 28.0(82.3-111.1)$ & 0.036 \\
\hline 24 hours & $250.0 \pm 83.8(217.6-282.5)$ & $176.4 \pm 53.2(156.2-196.7)$ & $<0.001$ \\
\hline \multicolumn{4}{|l|}{ Rescue analgesics requirement } \\
\hline Recovery room & $19(65.5)$ & $22(75.9)$ & 0.387 \\
\hline Ward & $2(6.9)$ & $4(13.8)$ & 0.670 \\
\hline Patient satisfaction (0-10) & $6.9 \pm 1.8$ & $7.8 \pm 1.4$ & 0.042 \\
\hline Postoperative nausea & $11(37.9)$ & $6(20.7)$ & 0.149 \\
\hline Postoperative vomiting & $3(10.7)$ & $4(14.8)$ & 0.705 \\
\hline Intermittent IV-PCA discontinuation & $21(72.4)$ & $26(89.7)$ & 0.094 \\
\hline
\end{tabular}

Values are presented as mean \pm standard deviation (95\% confidence interval) or frequency (\%).

Bonferroni correction was used for multiple comparisons.

IV-PCA: intravenous patient-controlled analgesia, ESPB: erector spinae plane block.

*Sum of intraoperative, rescue and IV-PCA opioid use. 
paravertebral space $[20,21]$. Similarly, clinical studies have had conflicting results. According to some studies, ESPB has an opioid-sparing effect and could be as effective as the thoracic paravertebral block (TPVB) in postoperative pain control for various types of thoraco-abdominal surgery [7-11], but there have been some reports that showed limited effect of the ESPB on postoperative pain control [12-14]. However, another cadaveric study has shown that the paravertebral spread following the ESPB depends on anesthetic volume, and that multiple levels of paraverte-

Table 3. Postoperative NRS scores at rest and on movement in the first 24 hours

\begin{tabular}{llcr}
\hline \multicolumn{1}{c}{ Outcomes } & $\begin{array}{c}\text { IV-PCA alone } \\
(\mathrm{n}=29)\end{array}$ & $\begin{array}{c}\text { IV-PCA plus ESPB } \\
(\mathrm{n}=29)\end{array}$ & $P$ value \\
\hline NRS at rest & & & \\
3 hours & $3(2-4)$ & $3(1-4)$ & 0.648 \\
6 hours & $3(3-4)$ & $3(2-4)$ & 0.632 \\
9 hours & $3(2-6)$ & $3(1-4)$ & 0.888 \\
24 hours & $2(2-4)$ & $2(1-3)$ & $>0.999$ \\
NRS on movement & & & \\
3 hours & $6(4-7)$ & $4(3-5)$ & 0.552 \\
6 hours & $7(5-8)$ & $5(3-7)$ & 0.212 \\
9 hours & $7(5-10)$ & $5(4-7)$ & 0.716 \\
24 hours & $5(4-7)$ & $4(3-6)$ & 0.120 \\
\hline
\end{tabular}

Values are presented as median (interquartile range). Bonferroni correction was used for multiple comparisons. NRS: numeric rating score, IV-PCA: intravenous patient-controlled analgesia, ESPB: erector spinae plane block. bral space would be affected if sufficient anesthetics (> $30 \mathrm{~mL}$ ) had been properly injected beneath the ESM [22]. This could be supported by a recently described mid-point transverse process to pleural block [23], the retrolaminar block [24], and the paraspinal block [25], all of which might be as effective as TPVB without a needle penetrating the superior costotransverse ligament, which is considered to be a barrier to the paravertebral space. Our results also suggest that injecting sufficient amount of anesthetics outside the paravertebral space could be an effective analgesic method.

Breast reconstruction surgery with implant often leads to moderate to severe postoperative pain, and most patients require high doses of opioids to relieve acute postoperative pain $[3,26]$. Most postoperative pain from mastectomy occurs within the first 24 hours after surgery [3]. Unlike mastectomy without an implant, a tissue expander insertion requires a pocket between the pectoral muscles. The pocket for the tissue expander can cause direct destruction of the pectoral nerves or lateral cutaneous branches of the intercostal nerves, since inflatable implants stretch and expand the pectoral muscle, fascia, and skin [26]. The important consideration, in postoperative pain control for breast surgery with implant, is that not only the intercostal nerves but also pectoral nerves are involved. Based on our findings that the difference between the groups in fentanyl consumption was only about $60 \mu \mathrm{g}$ and the mechanisms of ESPB that have been revealed to date, ESPB appears to block only the intercostal nerves

Table 4. The short form of brief pain inventory scores on 3 and 6 months after surgery

\begin{tabular}{|c|c|c|c|c|c|c|}
\hline \multirow[b]{2}{*}{ Parameters } & \multicolumn{3}{|c|}{3 months after surgery } & \multicolumn{3}{|c|}{6 months after surgery } \\
\hline & $\begin{array}{l}\text { IV-PCA alone } \\
\quad(n=24)\end{array}$ & $\begin{array}{l}\text { IV-PCA plus ESPB } \\
\quad(n=25)\end{array}$ & $P$ value & $\begin{array}{l}\text { IV-PCA alone } \\
\quad(n=24)\end{array}$ & $\begin{array}{l}\text { IV-PCA plus ESPB } \\
\quad(n=22)\end{array}$ & $P$ value \\
\hline \multicolumn{7}{|l|}{ Pain intensity } \\
\hline Presence of pain & $15(62.5)$ & $12(48.0)$ & 0.616 & $15(62.5)$ & $8(36.4)$ & 0.154 \\
\hline Worst pain & $1.9 \pm 2.1$ & $1.5 \pm 1.9$ & 0.982 & $1.7 \pm 1.6$ & $1.1 \pm 1.8$ & 0.610 \\
\hline Least pain & $0.2 \pm 0.5$ & $0.1 \pm 0.4$ & 0.992 & 0 & $0.1 \pm 0.2$ & 0.602 \\
\hline Average pain & $1.1 \pm 1.4$ & $0.8 \pm 1.2$ & $>0.999$ & $0.9 \pm 1.0$ & $0.7 \pm 1.2$ & 0.958 \\
\hline Current pain & $0.5 \pm 1.1$ & $0.3 \pm 0.6$ & 0.970 & $0.2 \pm 0.5$ & $0.1 \pm 0.3$ & $>0.999$ \\
\hline \multicolumn{7}{|l|}{ Pain interference with } \\
\hline General activities & $0.5 \pm 1.1$ & $0 \pm 0.2$ & 0.110 & $0.1 \pm 1.3$ & 0 & 0.080 \\
\hline Mood & $0.8 \pm 1.4$ & $0.7 \pm 2.2$ & $>0.999$ & $0.4 \pm 0.9$ & $0.5 \pm 1.5$ & $>0.999$ \\
\hline Walking ability & $0.1 \pm 0.4$ & $0.1 \pm 0.6$ & $>0.999$ & $0 \pm 0.2$ & $0.1 \pm 0.4$ & $>0.999$ \\
\hline Normal work & $0.8 \pm 1.4$ & $0.7 \pm 2.2$ & 0.198 & $0.5 \pm 1.3$ & $0.2 \pm 0.8$ & 0.606 \\
\hline Relations with other people & $0.4 \pm 1.1$ & $0.1 \pm 0.4$ & 0.342 & $0.1 \pm 0.4$ & 0 & 0.656 \\
\hline Sleep & $1.0 \pm 1.8$ & $0.2 \pm 0.7$ & 0.088 & $0.1 \pm 1.8$ & $0.1 \pm 0.4$ & 0.054 \\
\hline Enjoyment of life & $1.4 \pm 2.5$ & $0.6 \pm 1.4$ & 0.938 & $1.2 \pm 2.3$ & $0.3 \pm 1.0$ & 0.218 \\
\hline
\end{tabular}

Values are presented as frequency (\%) or mean \pm standard deviation.

Bonferroni correction was used for multiple comparisons.

IV-PCA: intravenous patient-controlled analgesia, ESPB: erector spinae plane block, NRS: numeric rating score.

Each item except for presence of pain is rated on NRS (from ' 0 ' = [no pain] to ' 10 ' [worst] or as ' 0 ' [no interference] to '10' [interferes completely]). 
among these nerves [27].

Inadequate acute postoperative pain management is well known to be a major risk factor for PPP $[5,16,28]$. Acute postoperative pain can be managed with the perioperative administration of opioids, either by IV injection or by a PCA device. However, inappropriate perioperative use of opioids obviously increases the incidence of opioid-related side effects including nausea, vomiting, overdose, and risk of addiction [28,29]. Furthermore, the opioid-sparing modality is a major discipline of Enhanced Recovery After Surgery (ERAS) protocols [28]. Thus, postoperative analgesia remains a challenge for these patients, despite the range of treatment options.

In the current study, intraoperative opioid consumption was also different between the two groups. During surgery, we administered $25 \mu \mathrm{g}$ of fentanyl intravenously when blood pressure was increased by $20 \%$ compared to baseline. When local anesthetics are used in nerve blocks and regional anesthesia, antinociceptive effect occurs by inhibiting excitation of nerve endings or by preventing the formation of action potential in the peripheral nerves [30]. Clinically, the stimulation of nociceptors may be reflected by increases in blood pressure [31]. Therefore, we thought the consumption of fentanyl was lower in the block group due to the antinociceptive effect of the LA agent. Preemptive analgesia means that pain control is more effective if administered before the surgical incision. Therefore, a fascial plane block such as ESPB might achieve this goal by blocking the conduction of surgical stimuli [32,33].

Meanwhile, the PCA was allowed to intermittently turn off if patients had nausea, vomiting, or little pain. As a result, cumulative PCA fentanyl consumption in group E during the first 24 hours would be less than $240 \mu \mathrm{g}$ (176.4 \pm $53.2 \mu$, Table 2).

There have been many studies in the literature about maintaining postoperative analgesia with regional anesthesia techniques after breast surgery. The TPVB and epidural block have been commonly accepted as an effective surgical anesthesia technique for breast surgery with favorable postoperative pain control. However, the TPVB carries the risk of potentially life-threatening complications including pneumothorax, hemothorax, epidural hematoma, and intrathecal injection, and clinicians are searching for a safer and easier alternative [23]. Recently, the pectoralis blocks and the serratus plane block were introduced for this purpose, and are known to have relatively good efficacy while being simple to do [34,35]. However, these blocks also might cause a lung parenchymal puncture, and can directly interrupt the surgical field [25]. Additionally, since the anterior cutaneous branch of the thoracic intercostal nerve and the supraclavicular nerve are difficult to block with these methods, it might be dif- ficult to control pain in broad surgical sites, including the anterior thorax [36]. Especially in postoperative pain control after breast surgery, the ESPB might yield a similar analgesic effect, with fewer complications when compared with the TPVB and the serratus plane block $[7,37]$. The ESPB also has less risk of direct spinal cord injury, epidural hematoma, pneumothorax, or central infection because of the strong barrier, the TP [38]. Therefore, the ESPB can be a safer technique with a superior analgesic effect in breast surgery.

In the current study, the ESPB did not significantly reduce the incidence of PONV, although it significantly reduced postoperative opioid use, perhaps because in our study there were other risk factors for PONV, such as gender, a prophylactic antiemetic regimen, and use of volatile anesthetics [39]. Also, in our study, the background infusion rate of fentanyl via the IV-PCA was about $50 \%$ of the usual dose, which might have affected the incidence of PONV [40].

This study has several limitations. First, patients and practitioners for procedure were not blinded to the study. Even if investigators involved in outcome assessment were blinded, patients knew about their block and the investigators might have known which procedures had been done for each patient during follow-up. For observing and comparing the placebo effect, it might be better to use a sham block in the control group. Second, we did not perform a pinprick and cold sensation test to find the blocked dermatome level for all subjects. The onset of the sensory block produced by ropivacaine $0.375 \%$ usually takes about 30 minutes or more, so it was difficult to check the blocked level before anesthetic induction in all subjects. Although we found a significant analgesic effect from the ESPB, adequate volumes or concentrations of local anesthetics have not yet been identified for the ESPB. Thus, spread level, optimal dose, and the concentration of local anesthetics should be evaluated in a future study. Third, chronic pain assessment was conducted by one investigator by telephone, rather than being completed by the subject directly in a written questionnaire. Finally, there was too small a sample size to demonstrate the difference in outcomes associated with PPP. Although a statistically significant difference could not be achieved, the low incidence of PPP at 3 and 6 months postoperatively in group E supported the established fact that adequately controlling acute surgical pain lowers PPP.

In conclusion, we found that the analgesic effect of the ESPB plus IV-PCA was better than that of IV-PCA alone after IBR with a tissue expander after mastectomy on the first postoperative day without significant complications. Thus, the ESPB could be one of the perioperative pain management options for breast reconstruction surgery. 


\section{ACKNOWLEDGMENTS}

Statistical analyses were performed in collaboration with Ho Jung Won and Seonwoo Kim from the Biostatistics Team of Samsung Biomedical Research Institute.

\section{CONFLICT OF INTEREST}

No potential conflict of interest relevant to this article was reported.

\section{FUNDING}

No funding to declare.

\section{ORCID}

Sukhee Park, https://orcid.org/0000-0002-8798-7578

Joohyun Park, https://orcid.org/0000-0002-9107-0826

Ji Won Choi, https://orcid.org/0000-0001-7403-2863

Yu Jeong Bang, https://orcid.org/0000-0002-1108-1155

Eun Jung Oh, https://orcid.org/0000-0001-6268-109X

Jiyeon Park, https://orcid.org/0000-0003-1267-0573

Kwan Young Hong, https://orcid.org/0000-0001-6213-1848

Woo Seog Sim, https://orcid.org/0000-0002-5346-6424

\section{REFERENCES}

1. Bray F, Ferlay J, Soerjomataram I, Siegel RL, Torre LA, Jemal A. Global cancer statistics 2018: GLOBOCAN estimates of incidence and mortality worldwide for 36 cancers in 185 countries. CA Cancer J Clin 2018; 68: 394-424.

2. Gassman AA, Yoon AP, Maxhimer JB, Sanchez I, Sethi H, Cheng KW, et al. Comparison of postoperative pain control in autologous abdominal free flap versus implant-based breast reconstructions. Plast Reconstr Surg 2015; 135: 356-67.

3. Caffo O, Amichetti M, Ferro A, Lucenti A, Valduga F, Galligioni E. Pain and quality of life after surgery for breast cancer. Breast Cancer Res Treat 2003; 80: 39-48.

4. Andersen KG, Duriaud HM, Jensen HE, Kroman N, Kehlet $\mathrm{H}$. Predictive factors for the development of persistent pain after breast cancer surgery. Pain 2015; 156: 2413-22.

5. Kehlet H, Jensen TS, Woolf CJ. Persistent postsurgical pain: risk factors and prevention. Lancet 2006; 367: 1618-25.

6. Forero M, Adhikary SD, Lopez H, Tsui C, Chin KJ. The erector spinae plane block: a novel analgesic technique in thoracic neuropathic pain. Reg Anesth Pain Med 2016; 41: 621-7.

7. Gürkan Y, Aksu C, Kuş A, Yörükoğlu UH. Erector spinae plane block and thoracic paravertebral block for breast surgery compared to IV-morphine: a randomized controlled trial. J Clin Anesth 2020; 59: 84-8.

8. Aksu C, Kuș A, Yörükoğlu HU, Tor Kılıç C, Gürkan Y. Analgesic effect of the bi-level injection erector spinae plane block after breast surgery: a randomized controlled trial. Agri 2019; 31: 132-7.

9. Taketa Y, Irisawa Y, Fujitani T. Comparison of ultrasoundguided erector spinae plane block and thoracic paravertebral block for postoperative analgesia after video-assisted thoracic surgery: a randomized controlled non-inferiority clinical trial. Reg Anesth Pain Med 2019. doi: 10.1136/rapm2019-100827.

10. Oksuz G, Bilgen F, Arslan M, Duman Y, Urfalıglu A, Bilal B. Ultrasound-guided bilateral erector spinae block versus tumescent anesthesia for postoperative analgesia in patients undergoing reduction mammoplasty: a randomized controlled study. Aesthetic Plast Surg 2019; 43: 291-6.

11. Hong B, Bang S, Chung W, Yoo S, Chung J, Kim S. Multimodal analgesia with multiple intermittent doses of erector spinae plane block through a catheter after total mastectomy: a retrospective observational study. Korean J Pain 2019; 32: 20614.

12. Kang R, Chin KJ, Gwak MS, Kim GS, Choi SJ, Kim JM, et al. Bilateral single-injection erector spinae plane block versus intrathecal morphine for postoperative analgesia in living donor laparoscopic hepatectomy: a randomized non-inferiority trial. Reg Anesth Pain Med 2019. doi: 10.1136/rapm2019-100902.

13. Altıparmak B, Korkmaz Toker M, Uysal Al, Turan M, Gümüș Demirbilek S. Comparison of the effects of modified pectoral nerve block and erector spinae plane block on postoperative opioid consumption and pain scores of patients after radical mastectomy surgery: a prospective, randomized, controlled trial. J Clin Anesth 2019; 54: 61-5.

14. Zhang J, He Y, Wang S, Chen Z, Zhang Y, Gao Y, et al. The erector spinae plane block causes only cutaneous sensory loss on ipsilateral posterior thorax: a prospective observational volunteer study. BMC Anesthesiol 2020; 20: 88.

15. Keller S, Bann CM, Dodd SL, Schein J, Mendoza TR, Cleeland CS. Validity of the brief pain inventory for use in documenting the outcomes of patients with noncancer pain. Clin J Pain 2004; 20: 309-18.

16. Wang $\mathrm{K}$, Zhang X, Zhang T, Yue H, Sun S, Zhao H, et al. The efficacy of ultrasound-guided type II pectoral nerve blocks in perioperative pain management for immediate reconstruction after modified radical mastectomy: a prospective, randomized study. Clin J Pain 2018; 34: 231-6.

17. Kot P, Rodriguez P, Granell M, Cano B, Rovira L, Morales J, et al. The erector spinae plane block: a narrative review. Korean J Anesthesiol 2019; 72: 209-20.

18. Adhikary SD, Bernard S, Lopez H, Chin KJ. Erector spinae 
plane block versus retrolaminar block: a magnetic resonance imaging and anatomical study. Reg Anesth Pain Med 2018; 43: 756-62.

19. Yang HM, Choi YJ, Kwon HJ, O J, Cho TH, Kim SH. Comparison of injectate spread and nerve involvement between retrolaminar and erector spinae plane blocks in the thoracic region: a cadaveric study. Anaesthesia 2018; 73: 1244-50.

20. Ivanusic J, Konishi Y, Barrington MJ. A cadaveric study investigating the mechanism of action of erector spinae blockade. Reg Anesth Pain Med 2018; 43: 567-71.

21. Dautzenberg KHW, Zegers MJ, Bleeker CP, Tan ECTH, Vissers KCP, van Geffen GJ, et al. unpredictable injectate spread of the erector spinae plane block in human cadavers. Anesth Analg 2019; 129: e163-6.

22. Choi YJ, Kwon HJ, O J, Cho TH, Won JY, Yang HM, et al. Influence of injectate volume on paravertebral spread in erector spinae plane block: an endoscopic and anatomical evaluation. PLoS One 2019; 14: e0224487.

23. Costache I, de Neumann L, Ramnanan CJ, Goodwin SL, Pawa A, Abdallah FW, et al. The mid-point transverse process to pleura (MTP) block: a new end-point for thoracic paravertebral block. Anaesthesia 2017; 72: 1230-6.

24. Murouchi T, Yamakage M. Retrolaminar block: analgesic efficacy and safety evaluation. J Anesth 2016; 30: 1003-7.

25. Roué C, Wallaert M, Kacha M, Havet E. Intercostal/paraspinal nerve block for thoracic surgery. Anaesthesia 2016; 71: 112-3.

26. Woodworth GE, Ivie RMJ, Nelson SM, Walker CM, Maniker RB. Perioperative breast analgesia: a qualitative review of anatomy and regional techniques. Reg Anesth Pain Med 2017; 42: 609-31.

27. Bang S. Erector spinae plane block: an innovation or a delusion? Korean J Anesthesiol 2019; 72: 1-3.

28. Chiu C, Aleshi P, Esserman LJ, Inglis-Arkell C, Yap E, Whitlock EL, et al. Improved analgesia and reduced postoperative nausea and vomiting after implementation of an enhanced recovery after surgery (ERAS) pathway for total mastectomy. BMC Anesthesiol 2018; 18: 41.

29. Kumar K, Kirksey MA, Duong S, Wu CL. A review of opioidsparing modalities in perioperative pain management: methods to decrease opioid use postoperatively. Anesth Analg 2017; 125: 1749-60.

30. Peker K, Akçaboy ZN, Aydın G, Gençay I, Şahin AT, Koçak YF, et al. The effect of erector spinae plane block on laparoscopic cholecystectomy anesthesia: analysis of opioid consumption, sevoflurane consumption, and cost. J Laparoendosc Adv Surg Tech A 2020; 30: 725-9.

31. Chen YA, Rivera-Serrano CM, Chen C, Chen YR. Pre-surgical regional blocks in orthognathic surgery: prospective study evaluating their influence on the intraoperative use of anaesthetics and blood pressure control. Int J Oral Maxillofac Surg 2016; 45: 783-6.

32. Erturk E, Aydogdu Kaya F, Kutanis D, Besir A, Akdogan A, Geze S, et al. The effectiveness of preemptive thoracic epidural analgesia in thoracic surgery. Biomed Res Int 2014; 2014: 673682.

33. Lee J, Kim S. The effects of ultrasound-guided serratus plane block, in combination with general anesthesia, on intraoperative opioid consumption, emergence time, and hemodynamic stability during video-assisted thoracoscopic lobectomy: a randomized prospective study. Medicine (Baltimore) 2019; 98: e15385.

34. Yao Y, Li J, Hu H, Xu T, Chen Y. Ultrasound-guided serratus plane block enhances pain relief and quality of recovery after breast cancer surgery: a randomised controlled trial. Eur J Anaesthesiol 2019; 36: 436-41.

35. De Cassai A, Bonanno C, Sandei L, Finozzi F, Carron M, Marchet A. PECS II block is associated with lower incidence of chronic pain after breast surgery. Korean J Pain 2019; 32: 286-91.

36. Kim DH, Kim S, Kim CS, Lee S, Lee IG, Kim HJ, et al. Efficacy of pectoral nerve block type II for breast-conserving surgery and sentinel lymph node biopsy: a prospective randomized controlled study. Pain Res Manag 2018; 2018: 4315931.

37. Wang HJ, Liu Y, Ge WW, Bian LD, Pu LF, Jiang Y, et al. [Comparison of ultrasound-guided serratus anterior plane block and erector spinae plane blockperioperatively in radical mastectomy]. Zhonghua Yi Xue Za Zhi 2019; 99: 1809-13. Chinese.

38. Tsui BCH, Fonseca A, Munshey F, McFadyen G, Caruso TJ. The erector spinae plane (ESP) block: a pooled review of 242 cases. J Clin Anesth 2019; 53: 29-34.

39. Cao X, White PF, Ma H. An update on the management of postoperative nausea and vomiting. J Anesth 2017; 31: 617-26.

40. Shin S, Min KT, Shin YS, Joo HM, Yoo YC. Finding the 'ideal' regimen for fentanyl-based intravenous patient-controlled analgesia: how to give and what to mix? Yonsei Med J 2014; 55: 800-6. 